\title{
“- ELA É NOSSA PRISIONEIRA!" - QUESTÕES TEÓRICAS, EPISTEMOLÓGICAS E ÉTICO-METODOLÓGICAS A PROPÓSITO DOS PROCESSOS DE OBTENÇÃO DA PERMISSÃO DAS CRIANÇAS PEQUENAS NUMA PESQUISA ETNOGRÁFICA
}

\author{
Manuela Ferreira ${ }^{1}$
}

\section{Resumo}

Subscrevendo os pressupostos da abordagem da Sociologia da Infância que considera as crianças como actores sociais e advoga a etnografia como uma metodologia útil para fazer ouvir as vozes das crianças na produção de dados sociológicos (James \& Prout 1990), reflectem-se neste texto algumas questões epistemológicas, teóricas, metodológicas e éticas inerentes à experiência no terreno com um grupo de crianças dos 3-6 anos, durante um ano lectivo, num Jardim de Infância (JI) localizado em meio urbano. A abordagem do princípio teórico e ético da obtenção do consentimento informado e da sua prática junto de crianças pequenas, visa discutir as tensões e os limites entre aquela noção e a de assentimento no decurso da observação participante. A análise de algumas configurações que o assentimento e as recusas por parte destas crianças podem assumir ao longo da pesquisa, procura evidenciá-lo como um processo contingente, heterogéneo e dependente da relação social de investigação que vai sendo construída bem como das interpretações que as crianças tecem acerca da pessoa da investigadora.

Palavras-Chave: Infância; metodologia de pesquisa, etnografia.

\footnotetext{
${ }^{1}$ Professora auxiliar na Faculdade de Psicologia e Ciências da Educação da Universidade do Porto, R. Dr. Manuel Pereira da Silva, 4200-392 Porto, mauela@fpce.up.pt

Revista Reflexão e Ação, Santa Cruz do Sul, v.18, n2, p.151-182, jul./dez. 2010
} 


\title{
1. “- Sapatos com salto, cair! Não tem... " - Introdução
}

\begin{abstract}
"No recreio, a Joana e a Bruna "comandavam" o jogo do "Um, dois, três, macaquinho chinês". Como habitualmente, fui convidada pelas crianças a juntarme a elas. A Mafalda, de frente para a parede, gritava rapidamente a lenga-lenga. Quando ela parava e se voltava para ver quem se tinha mexido, a Bruna, que tinha permanecido ao seu lado a observar-nos, apontava para quem se tinha deslocado e dizia: - Para trás!. O/a visado/a regressava ao início do percurso e o jogo recomeçava nos mesmos termos sem que alguém conseguisse alcançar a Mafalda. (...). A dada altura, enquanto me desloco, tropeço, desequilibro-me, tento recompor-me, volto a tropeçar e acabo estatelada no chão. As crianças olham para mim, entre espanto, o riso e a aflição, e eu, desconcertada, ainda sem perceber muito bem como é que "aquilo" me tinha acontecido, levanto-me rapidamente e tento "compor-me". Enquanto aperto o sapato, as crianças reparam que o meu joelho está esfolado, e o Bernardo diz-me: “- Sapatos com salto, cair! Não tem...”. (notas de campo, Junho, 1999).
\end{abstract}

Este excerto, que culmina com a minha queda e ocorre já no final do ano lectivo, quando estava quase a terminar o trabalho de terreno num Jardim de Infância (JI) ${ }^{2}$, é aqui usado como ponto de partida para abordar algumas questões epistemológicas, teóricas, metodológicas e éticas que se colocam na pesquisa etnográfica com crianças pequenas. Em particular, pretendo destacar essa faceta da etnografia que consiste na experiência de proximidade (Geertz, 1973/1999: 87-89) proporcionada pela observação participante, através da qual a investigadora se assume como o principal instrumento da pesquisa. Isto significa que o intuito etnográfico de "compreender a compreensão do Outro" (cf. Silva, 2001), se constitui como um processo interdependente e dialógico entre o sujeito-investigadora e o objecto de conhecimento-crianças. No seu cerne reside uma relação social de investigação, cuja estrutura e dinâmicas geracionais merecem uma especial atenção (cf. Mayall, 2000). Neste sentido, a minha queda reflecte uma experiência adulta de vulnerabilidade interceptada por interpretações recíprocas e mutuamente interferentes comigo própria e entre mim e as crianças: quando eu, na pessoa da própria investigadora, me debato interiormente e demoro a acreditar que, tal como as crianças também posso cair no chão, como se com isso tivesse

\footnotetext{
2 Tratou-se de um grupo heterogéneo grupo constituído por 18 crianças, com idades entre os 4 e os 5 anos na sua maioria rapazes, sendo oriundas de famílias urbanas da classe média alta.
} 
simbolicamente caído o meu estatuto social de adulto invertendo-se também os papeis na investigação, sendo observada, de cima, pelas crianças; e quando, nessas minhas identidades ainda me confronto com a "lição de moral" sintetizada pelo Bernardo para me fazer saber que, enquanto adulto que usa "sapatos com salto"3 até posso ser capaz de brincar como elas, “tornando-me como" como elas, mas precisamente porque já não sou criança e as crianças não usam "saltos" quando brincam, sujeito-me a tropeçar, ou seja, a cometer gaffes e, com isso, a "perder a face" (Goffman, 1993). Por outras palavras, apesar da centralidade que o tempo da relação assume nos esforços continuados de aproximação dos adultosinvestigadores para esbaterem as suas diferenças físicas e culturais e compreenderem a "outridade" das crianças, nem os adultos deixam de ser adultos, nem as crianças deixam de ser crianças, nem tão pouco ambos abrem mão facilmente das suas concepções e expectativas acerca do que é um adulto e do que é uma criança.

Ao retratar e simbolizar, de algum modo, o posicionamento adulto numa pesquisa etnográfica que se pretendia "com as crianças e não sobre as crianças" (cf. Christensen \& James, 2000), a minha queda torna-se então na justificação para, nesta configuração metodológica, reflectir as negociações de sentidos que a etnógrafa e as crianças accionam aquando do seu acesso aos mundos sociais infantis, e as relações de interdependência e alteridade que permeiam as suas identidades nos encontros intersubjectivos. Assim, após a explicitação dos pressupostos teóricos que, no quadro da Sociologia da Infância, enlaçam as pesquisas das crianças como actores sociais com a etnografia, procura-se questionar algumas das suas prerrogativas-chave. Seguidamente, e de entre os inúmeros tópicos que se oferecem à reflexão epistemológica, metodológica e ética inerente ao trabalho de observação

\footnotetext{
3 Não se tratam, literalmente, de sapatos de salto alto, como a expressão do Bernardo sugere, mas sim de sapatos apenas com um pequeno tacão largo, mas que, definitivamente, são diferentes das botas ou sapatilhas que as crianças costumavam usar. Neste sentido, creio ser plausível a interpretação de que, para todos os efeitos, eram, genericamente, sapatos considerados de mulher adulta e não de criança.
} 
participante no terreno, equacionam-se i) as dificuldades em satisfazer o princípio do consentimento informado voluntário com o da observabilidade directa e "natural", quando os actores em causa são crianças pequenas; ii) as complexidades que os princípios da privacidade e confidencialidade encerram quando as acções sociais das crianças ocorrem num espaço público e colectivo como o JI, e iii) a importância de obter a permissão das crianças de um modo compreensivo e contextualizado ao longo da pesquisa. A abordagem das facetas que estas questões se revestiram ao longo da pesquisa etnográfica com crianças apoia-se na análise de alguns episódios em que me deparei com a vivência de sentimentos ambíguos e dilemas (Ferreira, 2003, 2004; Skånfors, 2009), a gestão das impressões no terreno (Goffman, 1993) e o trabalho emocional (Cabral, 1983). No desvelar deste outro lado da etnografia, considerando-me a mim própria como objecto de reflexividade metodológica para me pensar e pensar-me na relação com aqueles Outros-crianças pequenas, procura-se desmitificar a retórica que assumiram alguns pressupostos teóricos relativos à pesquisa com crianças. Pretende-se, com isso, contribuir para i) a reconstrução possível das categorias sociais da infância e adultez consciencializando, na insuperabilidade das respectivas diferenças e na compreensão sempre parcial do Outro, os poderes relativos que adultos e crianças jogam nos seus encontros sociais; e ii) sublinhar o potencial que se encerra nessa alteridade para produzir conhecimento crítico, reflexivo e transformador acerca de ambos.

\section{crianças \\ 2. Inverter o olhar e conhecer a realidade social a partir da infância e das}

Numa história do estudo da infância nas Ciências Sociais que tem sido marcada não por uma ausência de interesse pelas crianças, mas pelo seu silêncio (cf. James \& Prout, 1990), a originalidade da Sociologia da Infância ou dos novos Estudos Sociais da Infância radica no seu desafio a uma ruptura epistemológica em que confluem a interdependência conceptual e prática entre infância e crianças e a inversão da perspectiva de análise social 
sobre o conhecimento da realidade contemporânea a partir da infância e das interpretações e questionamentos que as próprias crianças elaboram acerca das suas circunstâncias de vida e do mundo social. Isto significa entender a infância, simultaneamente, como uma categoria socio-histórica geracional, como uma estrutura geracional e como um espaço social dentro do qual as crianças, enquanto actores individuais e colectivos empenhados em agir nos seus mundos de vida se constituem activamente como crianças. A sua tradução ao nível teóricometodológico significa que nas pesquisas que perspectivam as crianças como actores sociais elas são a unidade de estudo directo e basilar, que a sua autonomia e equidade conceptual é assumida como legítima, que as suas interacções sociais são a unidade de análise privilegiada e que o princípio da simetria ética com os adultos ${ }^{4}$ (cf. James \& Prout 1997; Corsaro, 1997, Christensen \& James, 2000; Prout, 2000) deverá ser observado de modo cuidado e reflexivo. Por outras palavras, a imprescindibilidade de conhecer as crianças a partir da escuta da(s) sua(s) voz(es) constitui-se, no plano epistemológico, numa questão decisiva (cf. Lloyd-Smith \& Tarr, 2002: 61), porque se admite que as próprias experiências das crianças do que é ser criança e do que é a sua relação com os adultos são contributos inestimáveis para entender a infância, para "repensar a teoria estabelecida e as fronteiras conceptuais em que assentam as relações geracionais" (Ferreira \& Rocha, 2010: 1) e para "melhorar a compreensão de como a ordem social funciona" (Mayall, 2000: 130).

\footnotetext{
4 Prout (2002: X) refere como um dos contributos iniciais aportadas pelos "novos" estudos sociais da infância o que designa como "primeira simetria", ie, o questionamento das divisões, distinções e oposições apriorísticas e tomadas como certas entre "adultos" e "crianças", apontando, mais recentemente, para a necessidade das pesquisas darem conta do que designa de "segunda simetria", ie, o questionamento das distinções e oposições entre "crianças" e "infầncia", considerando que "tal divisão é inaceitável porque faz com que "crianças" e "infância" pareçam objectos de análise diferentes". Conceber as crianças como seres humanos semelhantes aos adultos mas possuindo competências diferentes é então admitir que as concepções e interpretações adultocêntricas, sendo recíprocas entre adultos-investigadores e crianças, interferem amplamente nos modos como ambos se percepcionam e relacionam, pelo que, ao nível metodológico, a recomendação básica é proceder tal como noutra pesquisa das Ciências Sociais, por exemplo, com adultos: ter a preocupação de que os métodos são os adequados às pessoas envolvidas no estudo, às questões centrais da pesquisa e ao seu contexto social e cultural - "as práticas usadas na pesquisa devem estar de acordo com as experiências das crianças, os seus interesses, valores e rotinas quotidianas" (cf. Christensen \& James, 2000: 484).
} 
Sendo que um dos papéis relevantes da pesquisa é "desafiar os significados e os modelos envolvidos na teoria prevalecente, questionar os taken-for-granted das assunções sociais e crenças e analisar criticamente os discursos formais sobre os fenómenos sociais" (Lloyd-Smith \& Tarr, 2002: 59), em causa está o (re)conhecimento da infância, com base na sua alteridade face aos adultos, de modo a interpelar as concepções que a vêem apenas como um facto natural e biológico, tanto mais insignificante cultural e socialmente porque reportado a seres "menores", as crianças. Deste ângulo, as relações inter e intrageracionais tornam-se o objecto de estudo de eleição, perspectivado a partir das suas diferenças e interdependências sociais para aí se descobrirem os conteúdos, e os fluxos e circulação de sentidos d"“isso" de se ser e de se tornar criança nos que, como, quando, onde e com quem elas pensam, fazem e sentem com outras crianças e os adultos. Trata-se de apreender a heterogeneidade interna e a pluralidade de infâncias constitutiva d(n)este espaço e categoria social, e de compreender os processos que constróem e dão sentido às densas relações sociais das crianças na infância. É no âmbito destes pressupostos conceptuais que a máxima, “a etnografia é uma metodologia particularmente útil porque permite captar uma voz mais directa das crianças e a sua participação na produção de dados sociológicos" (James \& Prout, 1990: 4, 8), encontra a sua justificação. Pode então dizer-se que, entre outros, o valor epistemológico dos adultos escutarem a(s) voz(es) das crianças para as tentarem compreender nos seus próprios termos, se afigura numa oportunidade para "descerem dos seus sapatos com salto" e virem conhecerem a realidade social a partir delas e da infância. A adesão a este desafio epistemológico requer, no entanto, a problematização de questões de natureza teórica, metodológica e ética a propósito daquela que se tornou uma trindade conceptual de referência da Sociologia da Infância - "as crianças como actores sociais", o "dar voz às crianças" e a "etnografia com crianças" -, sob pena dela se converter numa nova ortodoxia na pesquisa etnográfica com crianças (cf. Qvortrup, 2000; James, 2007). 


\subsection{Concertos e desconcertos a propósito das crianças como actores sociais, da(s) suas voz(es) e da etnografia com crianças}

A conceptualização das crianças como actores sociais supõe, pelo menos, uma dupla significação: i) elas são seres humanos com poder de simbolização e reflexão, de tomadas de iniciativa para a acção e acção social, não apenas activamente implicadas na construção das suas próprias vidas, mas também nas daqueles com quem se relacionam e que as rodeiam, e na da sociedade em que tomam parte, quando experimentam e aprendem a lidar com as possibilidades e os constrangimentos das estruturas sociais no quotidiano; ii) enquanto seres humanos elas são intrinsecamente seres sociais que, sujeitas à socialização da cultura adulta a reproduzem, não obstante serem igualmente capazes de a reinterpretar consoante os seus interesses, desejos, entendimentos, lógicas, crenças e valores individuais e/ou colectivos e, através disso, de a reconfigurar em sistemas organizados geradores de culturas e ordens sociais infantis e, mais ainda, de convocar e gerir estrategicamente ambas as culturas de modos tão variados quantos os interlocutores e as conjunturas que enfrentam. Sendo actores sociais auto e hetero-construídos no plano cognitivo e cultural, (re)produzem sentidos na/sobre a vida social cuja proliferação e manutenção com e ao lado de interacções intra e intergeracionais em contextos concretos influenciam as suas circunstâncias sociais de existência, são por elas influenciados e podem ainda instituir outras que alteram o próprio espaço social da infância.

Creditar as crianças como actores sociais e com o direito de se apresentarem como sujeitos de conhecimento nos seus próprios termos, sendo indissociável do seu reconhecimento como produtoras de sentido, é então assumir como legítimas as suas formas de comunicação e relação, mesmo que estas se expressem diferentemente das que os adultos usam habitualmente, para nelas se ser capaz de interpretar, compreender e valorizar os seus aportes como contributos a ter em conta na renovação e reforço dos laços sociais nas 
comunidades em que participam. Ou seja, as crianças têm "voz" porque têm "coisas" ideias, opiniões, críticas, experiências, .... - a dizer aos adultos, verbalmente ou não, literalmente ou não, mas estes só poderão ter acesso a esse pensamento e conhecimento se estiverem na disposição de suspender os seus entendimentos e cultura adultos para, na medida do possível, aprenderem com elas os delas e assim compreenderem o sentido das suas interacções no contexto dos seus universos específicos. $\mathrm{O}$ desenvolvimento da intersubjectividade para a construção de um sentido contextual comum torna-se então parte integrante do processo de deixar-se socializar na(s) sua(s) cultura(s). Colocada a diferença cultural como questão de fundo nos assuntos geracionais, melhor se compreende assim porque, do ponto de vista epistemológico e metodológico, as etnografias com crianças são recomendadas 5 .

Não obstante adultos e crianças partilharem uma ontologia como seres humanos intrinsecamente bio-socioculturais em processo, distinguem-nos diferenças físicas de tamanho, de tempo, experiêncis e conhecimentos de/a vida, a que se fazem corresponder atributos, expectativas, competências, papeis, funções e responsabilidades sociais diferentes. Assim, nunca é demais relembrar que a pesquisa em Ciências Sociais, enquanto produto e produção humana, foi e é sempre conduzida e produzida por adultos. Por conseguinte, importa retomar as imbricadas relações entre "etnografia com crianças" e "a voz". No primeiro caso, para reafirmar que não havendo encontro intercultural com o "Outro" sem interacções continuadas entre o investigador-adulto e os sujeitos-crianças investigados, sendo estas marcadas por diferentes culturas e desiguais saberes, competências, poderes e

\footnotetext{
5 Com efeito, elas são copiosas em descrições e análises que tanto têm evidenciado a diversidade de infâncias e de experiências sociais das crianças nas escolas e nas famílias, mas também entre e para além delas, incluindo a pertinência que aí têm as dimensões de género, classe social, etnia ou idades, como têm ultrapassado noções monolíticas, abstractas e reificadas da sua agência, substanciando as inúmeras formas, estilos e lógicas que as crianças imprimem às suas acções sociais quando estão a confrontar-se com os limites e virtualidades dos contextos heterogéneos em que se encontram e movem no quotidiano, incluindo a complexidade daquilo que nelas pode coexistir como perturbador e como perpetuador da reprodução e desigualdades sociais.
} 
identidades, a sua tradução no terreno, sobretudo pela prática da observação participante, acarreta que a selecção, interpretação e representação dos dados etnográficos é sempre levada a cabo pelo investigador-adulto. Assim sendo, de acordo com Brack-Lamy (2009: 13-14), a pesquisa etnográfica resulta "de um encontro com a alteridade e este encontro representa não apenas o "Outro", mas a forma de lidar com a alteridade e com a relação entre ela e a teoria. Cada experiência etnográfica é uma experiência pessoal de relacionamento intersubjectivo e, por ser pessoal e única, significa que cada etnografia, enquanto "trabalho de campo" e enquanto texto, é uma solução pessoal possível entre várias, no sentido de dar conta do que foi observado e ouvido e o de o traduzir como significado antropológico". De crucial importância é então compreender que, o(a) investigador(a)-adulto, "ao observar e interagir nas várias situações que circunscrevem o universo social que estuda, confronta-se constantemente com a sua identidade e as identidades daqueles que estuda" (idem, 30), o que implica processos de negociação “entre as múltiplas referências que compõem o conjunto das representações de cada sujeito envolvido no processo (...), [incluindo] as vicissitudes do encontro subjectivo que ele supõe" (idem, 29). São estas negociações que facultam a heterossocialização, a culturalização, a relativização do adultocentrismo em presença e a diferença geracional. No segundo caso, para reiterar, de acordo com Ferreira e Rocha (2010: 3), que a "a declaração intencional de "dar voz às crianças" não significa por si só ou a priori que as crianças possam falar nem que todas elas o façam ou que falem sobre o que querem, nem garante que mesmo falando elas sejam ouvidas ou que o que têm para dizer seja interpretado em conformidade". Aqui, também é crucial não confundir a fala ou o ter condições para falar com "ter voz", nem reduzir a multivocalidade representada e até mesmo expressa por cada actor-criança nas suas vozes socialmente desiguais a um uníssono (cf. idem). São os sentidos subjectivos que aquelas vozes infantis ecoam que importam, mas 
estes, comunicados muito para além do verbo e da oralidade, nunca podem ser absolutamente compreendidos pela inferência adulta.

O estatuto e o posicionamento das crianças no grupo social de pares, o seu recorte e/ou a composição etária, de género e classe social, a heterogeneidade das suas experiências, bem como a idade, género e classe social do(a) investigador(a), as opções metodológicas que elege para captar a(s) "voz(es)" infantis e para a(s) representar na pesquisa, o seu papel e estatuto de poder e saber adultos, o leque de papéis que vai adoptando e/ou de que se vê investido, as estratégias que acciona, os percalços que sofre e as dúvidas e dilemas que o(a) assaltam no decurso da experiência no terreno, são aspectos que, imiscuidos na relação social de investigação, geram problemas conceptuais, epistemológicos e éticos em torno da observabilidade metodológica das acções sociais das crianças pelo adulto-investigador. Ora, pesquisar as crianças não é só uma questão de fazer opções teoricamente ajustadas: tudo se joga nos processos e relações que se vivem no trabalho científico no terreno e esses, porque contingentes, conjunturais e fluídos, jamais serão completamente previsíveis à partida pelo(a) investigador(a). O mesmo acontece em relação às questões éticas da pesquisa: os princípios e códigos éticos são importantes mas, como afirma Small (2001, cit in Gallagher, 2009: 13), "não nos ajudam a compreender como é que as decisões éticas são tomadas nos contextos específicos". A dispersão e diversidade que afectam a experiência etnográfica (cf. Jenks, 2000: 6), nem sempre esclarecida nos textos etnográficos, deixa a relação social de investigação envolta numa espécie de nublosa que aqui se reflecte a propósito da prática ética da obtenção do designado consentimento informado e da privacidade das crianças.

\subsection{A questão do consentimento informado de crianças pequenas: consentimento informado ou assentimento?}

A importância da prática ética do consentimento informado das crianças, já com tradição no campo da Medicina, só mais recentemente se tem feito sentir no campo das 
Ciências Sociais, tendo-se tornado imprescindível nas pesquisas em Sociologia da Infância (cf. Alderson \& Morrow, 2004). Aqui merecem, e têm merecido, particular atenção os dilemas e tensões que interceptam a dimensão ética da observabilidade metodológica das crianças já que a natureza da sua legitimidade como dependente, sobretudo, da obtenção do consentimento informado e voluntário dado por elas (Alderson \& Morrow, 2004; Cocks, 2006; Skånfors, 2009) e do respeito pela sua privacidade, visam subscrever e ratificar os seus direitos como pessoas na pesquisa, à luz da Convenção dos Direitos das Crianças (1989).

Visando salvaguardar os direitos de protecção das crianças, a prática ética da pesquisa procede primeiramente junto dos adultos seus responsáveis com vista à obtenção do seu consentimento informado, associando-se-lhe um conjunto de deveres e responsabilidades adultas relativos à salvaguarda da sua privacidade, anonimato e confidencialidade. A justificação para tal deve-se ao estatuto social de menoridade atribuído às crianças, em virtude de terem idades abaixo das do consentimento legal. Por outro lado, no que concerne à obtenção do consentimento informado das crianças, o que está em causa são os seus direitos de participação, onde se incluem, entre outros, os direitos a ser informada e a ser ouvida em assuntos que lhe dizem respeito ${ }^{6}$. Estes direitos e respectivos princípios éticos expressam continuidades, mas também mudanças no entendimento das crianças e, por consequência, nas relações entre adultos-investigadores e crianças, dado que estas são agora conceptualizadas não como meros objectos de investigação, mas como sujeitos com direitos e actores sociais capazes de interpretar o que se passa, de decidirem ou não a sua participação, e de, com as suas formas de interpelação, influenciarem e/ou intervirem activamente nos contornos que a pesquisa vai adquirindo. Neste sentido, de acordo com Smith (1975 cit in Robson \& Robson, 2002: 100), o consentimento informado na pesquisa "é constituído por três elementos: em primeiro lugar, a responsabilidade do investigador em assegurar aos participantes o

\footnotetext{
${ }^{6}$ Cf. os direitos de Participação das Crianças, patentes na CDC, nos artigos $12^{\circ}$ e $13^{\circ}$
} 
entendimento acerca do que a participação na pesquisa envolverá; em segundo, que os participantes não são forçados a participar; e por fim que os participantes têm completa liberdade para rever a sua decisão em participar e retirar a sua participação a qualquer momento". A validade do consentimento - ad sentire, ser do mesmo sentimento, estar de acordo $^{7}$ - implica então que o mesmo é devidamente informado e dado livremente, sem quaisquer pressões como a coerção, ameaças ou persuasão (cf. Alderson \& Morrow, 2004: 96) e que é renegociável (cf. Gallager, 2009: 16).

Ainda que estas assunções gerais reunam o consenso teórico, importa relembrar, no entanto, as palavras de Fine \& Sandstrom (1988: 11) de que se torna "difícil, se não impossível, discutir o estudo das crianças, abstraindo da análise das suas idades. Parece absurdo discutir técnicas, colocando na mesma rubrica idades entre os 2 e os 17 anos". Este alerta para as diferenças intrageracionais que a categoria infância integra requer da obtenção do consentimento informado das crianças redobrados esforços, cuidados de atenção e sensibilidade por parte dos(as) investigadores(as), dado que os problemas são saber até que ponto a sua permissão é ou não devidamente informada e, ainda, até que ponto ela é voluntária. Em causa tem estado o debate em torno da noção de competência das crianças para entenderem completamente a pesquisa e todas as suas implicações, e as reticências colocadas tendem a agravar-se tanto mais quanto mais pequenas elas forem, devido aos limites da sua linguagem verbal, da sua compreensão e da sua experiência social. Que os próprios adultos também enfrentam limites para traduzir a pesquisa em termos minimamente inteligíveis para elas e/ou em interpretar a sua aceitação, são igualmente outras questões relevantes a colocar mas estas nem sempre têm merecido a mesma atenção. Ora, dadas as dificuldades enfrentadas de parte a parte nas pesquisas com crianças pequenas não se pode

\footnotetext{
7 In Machado (1952), Dicionário Etimológico da Língua Portuguesa com a mais antiga documentação escrita e conhecida de muitos dos vocábulos estudados, vol II, pp: 213
} 
considerar, que elas ou que todas elas foram/estão plenamente informadas acerca dela para consentirem em seu próprio benefício, e é igualmente muito discutível até que ponto tal decisão é voluntária e resultante de uma ponderação atempada. Nestes termos, insistir e persistir acriticamente na ideia de consentimento informado, tal como tem sido definido por e para os adultos 8 , é correr o risco de fazer dele um uso "politicamente correcto" mas adultocentrico, uma vez que, de acordo com Cocks (2006: 253), “[a] definição de consentimento informado evoluiu a partir de uma concepção que permanece focada na criança dominante, que se presume tenha uma idade-canal de comunicação apropriado que os adultos conhecem e compreendem". Dado que o consentimento só é considerado válido "quando os participantes estão informados sobre, e entendem, a natureza, finalidades e, eventualmente, consequências da pesquisa" (Lindsay, 2000: 12; Masson, 2000: 40; Alderson \& Morrow, 2004; Gallagher, 2009: 15), será que nas pesquisas com crianças pequenas se pode falar em consentimento ou apenas de assentimento?

Na discussão que Alderson \& Morrow (2004: 97) tecem acerca destes dois termos, o assentimento é considerado em três acepções: "aceitação por menores que não têm idade legal para o direito de consentimento; aceitação por crianças que entendem algumas mas não todas as questões centrais requeridas pelo consentimento; aceitação pode significar "pelo menos não recusar". Sendo entendido pelas autoras como denotativo de uma "menor" competência das crianças do que o consentimento, e por isso preterido por elas, importa reflectir acerca da primeira acepção, que radica no estatuto legal das crianças, para considerar que ambos, consentimento e assentimento, em termos práticos, não diferem nem prescindem daquele que é um dos requisitos prévios de qualquer pesquisa com crianças: a obtenção da

\footnotetext{
8 Gallagher (2009: 17) na sequência da sua análise das dificuldades dos adultos em negociarem com as crianças o consentimento informado, afirma "Além do mais, o consentimento informado é uma invenção dos adultos, e uma que, historicamente, repousa sobre os brancos, da classe média, ocidentais e noções masculinas de contratualidade e direito".
} 
autorização formal dos adultos seus responsáveis ${ }^{9}$. Em relação à segunda acepção, ela reenvia à concepção de competência e ao que conta como competência das crianças pequenas, obrigando a contrapor às posições essencialistas a sua relativização como interdependente das suas experiências e conhecimentos para compreender e saber adequar-se in situ e no "aqui e agora" das ocasiões e dos encontros com que se depara, contextualizandoos ${ }^{10}$. Ao mesmo tempo, obriga a ter presente, tal como já se referiu acerca das dificuldades do(a) próprio(a) investigador(a) em explicitar a pesquisa e antecipar todas as suas consequências sociais e políticas, que esta acepção não é exclusiva das crianças pequenas: ela também se estende frequentemente aos adultos; não impedindo, portanto, que apenas entendendo parte da informação que lhes foi prestada umas e outros reelaborem interpretações acerca do que trata a pesquisa e lhe atribuam inúmeros sentidos. O mesmo acontece em relação à terceira acepção: à semelhança do que já se avançou em relação à "voz", ela levanta o problema de saber até que ponto as crianças têm ou não condições, tempo e meios para dizerem não, e/ou até que ponto as suas recusas se expressam nãoverbalmente e/ou, ainda, até que ponto o(a) investigador(a) as consegue interpretar convenientemente ou, pelo menos, ser sensível a elas. Não recusar, ou como diz o ditado popular, "Quem cala, consente”, não significa necessariamente aceitar, ou aceitar passivamente, do mesmo modo que afirmar verbalmente "não" pode não ter o significado inequívoco de recusa efectiva pois muitos poderão ser os seus sentidos e esses só são, eventualmente, apreensíveis no contexto da relação e das circunstâncias particulares em que ocorre. Por todas estas razões, nas pesquisas com crianças pequenas, mais do que falar em consentimento informado, talvez seja mais produtivo falar em assentimento para significar

\footnotetext{
9 Autorização esta que, aliás, é também fundamental para salvaguardar o(a) próprio(a) investigador(a).

10 A propósito da pesquisa com crianças "deficientes" e da obtenção do consentimento informado, Cocks (2006: 254-257) apresenta uma perspectiva crítica ao modo como a "agência", e mais especificamente, a "competência" têm sido definidas na Sociologia da Infância, advogando a necessidade de incorporar àqueles conceitos a incompetência, a dependência, a imaturidade e a incompletude que são inerentes à ambiguidade ontológica.
} 
que, enquanto actores sociais, mesmo podendo ter um entendimento lacunar, impreciso e superficial acerca da pesquisa, elas são, apesar disso, capazes de decidir acerca da permissão ou não da sua observabilidade e participação, evidenciando assim a sua agência - é o que se procura dar conta, seguidamente.

\section{Entre a teoria e a prática do trabalho etnográfico com crianças pequenas: compreender os assentimentos das crianças pequenas}

Apesar das recomendações teórico-metdológicas da etnografia com crianças enfatizarem a importância dos investigadores-adultos desconfiarem das distinções socialmente estabelecidas entre adultos e crianças e, em alguns casos, a irem até mais longe pelo accionamento de estratégias que visam delibradamente contrariá-las - o "papel mínimo de adulto" (Mandell, 1991), o "papel do adulto atípico" (Corsaro, 1985) ou o "papel do adulto pouco comum" (Christensen, 2004) -, são as diferenças incontornáveis e sempre remanecentes que, nessa alteridade, são constitutivas do conhecimento que se produz. Reclamam, por isso, o accionamento da reflexividade metodológica em torno dos referenciais teóricos e éticos em que se fundamenta a pesquisa e as acções do(a) investigador(a), e dos modos como emprega e lida com eles no decurso da prática etnográfica da observação participante com crianças pequenas em contexto educativo institucional.

\subsection{Assentimento inicial como modo de permissão geral e de circunstância}

Como já foi referido, um dos momentos cruciais da pesquisa etnográfica com crianças em contextos educativos institucionais, como o JI, é o acesso e a negociação da entrada do(a) investigador(a) no terreno de um modo aberto (Fine \& Sandstrom, 1988), e isso só aconteceu após a obtenção de sucessivas autorizações por parte dos adultos legalmente responsáveis pelas crianças, os respectivos encarregados de educação, a hierarquia institucional e a educadora. A análise desse primeiro encontro com as crianças procura evidenciar como, mais 
do que o seu consentimento informado, o que obtive foi apenas o seu assentimento geral e de circunstância:

\begin{abstract}
"Quando entro na sala, a educadora indica que me junte às crianças que já estavam sentadas em roda, dizendo-lhes: - Hoje temos aqui duas surpresas! Vamos lá ver se vocês são capazes de adivinhar... As crianças depressa apontaram para o Alex que, como eu, vinha pela primeira vez ao JI. Feitas as apresentações do Alex, a educadora insistiu: - E mais? Já repararam bem? As crianças olharam para mim, até que alguém me aponta, dizendo: - É ela! O Tiago perguntou-me: - Como é que te chamas? Nem tive tempo de responder porque outra criança disse-me: Põe-te em pé!, seguindo-se um coro: - Isso, isso, põe-te em pé! Completamente apanhada de surpresa, senti-me embaraçada, mas acabei por me levantar. Com aqueles 18 pares de olhos cravados em mim, disse-lhes o meи nome e que pretendia saber o que faziam quando estavam no JI, perguntando-lhes se as "podia ficar a ver enquanto brincavam..." e informando-as que "ia precisar de usar um caderno para escrever para não me esquecer". Nessa altura, entre o coro de "sins", a Bruna gritou: - Não!, mas acabaram todos a entoar: "- Siiiiiiiiiim-iiimiiim!”. O que me passou pela cabeça foi qualquer coisa como: e agora? Faço o quê? Isto não começa nada bem - era o meu sentimento geral -, mas ainda assim, perguntei, cheia de dúvidas: - É mesmo sim?”. “- É! É! É! - diziam em coro, e cada vez mais alto, até serem interrompidas pela educadora que começou a cantar a canção do "Bom dia". Aliviada, sento-me e também vou cantando. Quando terminámos, as crianças dispersaram-se pela sala e um pequeno grupo de rapazes chama-me para ir jogar dominó (...)”. (notas de campo, Outubro, 1998, $1^{\circ}$ dia)
\end{abstract}

O que me aconteceu com este grupo de crianças foi radicalmente diferente daquilo que esperava que acontecesse ${ }^{11}$. Desde logo, a apresentação dos recém-chegados, o Alex e eu, gerou um tratamento distinto por parte do grupo de crianças, denotando o estatuto diferente que atribuiram a cada um de nós. O que começou por ser um comportamento social comum, expressando curiosidade e interesse em saber o nome, derivou, no meu caso, num clamor colectivo para me colocar de pé, a que, embora contrariada, acedi. Ali estava eu a tentar agir em consonância com as recomendações de etnógrafos de crianças como Mandell (1988), Fine \& Sandstrom (1988), Corsaro (1995), procurando sublinhar as minhas intenções mais através de acções do que por um extenso uso da palavra e, com isso, a gerir as impressões (Goffman, 1993); querendo mostrar a todos(as), crianças e educadora, que embora ciente da impossibilidade de iludir as diferenças físicas, sociais e culturais pretendia, com a minha presença adulta, não desautorizar a segunda, não me confundindo nem

11 Com um outro grupo de crianças das mesmas idades, mas num JI em meio rural, tinha experimentado exactamente o oposto: aquilo que designei por "o travo do silêncio" (cf. Ferreira, 2003, 2004, 2008).

Revista Reflexão e Ação, Santa Cruz do Sul, v.18, n2, p.151-182, jul./dez. 2010 
concorrendo contra ela e, ao mesmo tempo, aceitar e respeitar ao máximo as iniciativas das primeiras em relação a mim, crendo que só assim poderia iniciar uma relação na base da confiança para poder vir a aceder à sua cultura.

Experimentando as dificuldades sentidas por outros investigadores em explicar “completamente", e à partida, a pesquisa a crianças pequenas 12 , e, ainda mais, as suas implicações futuras (cf. Fine \& Sandstrom, 1988; Ferreira, 2004), acabei por informá-las de um modo parcial, relevando apenas o que entendi ser pertinente para poderem tomar uma posição: "o que" pretendia - o tema central da pesquisa - e o "como" - observação a descoberto, directa e o seu registo "a quente" (Silva, 2001; Ferreira, 2003, 2004, 2008). Quando procurei perceber e, depois, confirmar a sua receptividade, fui confrontada com uma espécie de "provas" e provações sucessivas em torno da minha pessoa: transitei da autopercepção de me ver e sentir alvo curiosidade, e até de um certo interesse, a uma dupla conversão: primeiro, numa espécie de "atracção de feira", excrutinizada da cabeça aos pés por via da observação directa infantil e, depois, em recurso disponível para um "ajustamento secundário" (Goffman, 1961/1974), quando me torno pretexto para ressignificarem aquela reunião num momento de galhofa colectiva. Até aqui, as iniciativas e as atitudes desinibidas destas crianças face à minha presença podem ser interpretadas como formas de estarem a tentar perceber quem era eu e quais os meus papéis - seria uma nova educadora, uma nova auxiliar ou uma nova estagiária?13 -, e/ou de estarem a "medir" até onde eu me dispunha a ir, "palpando" os meus limites, e/ou a inferir que tipo de relação iria ser a nossa, e/ou a fazerem-

\footnotetext{
12 Esta observação significa, por um lado, que muitas vezes, no início do trabalho etnográfico, ainda que o/a investigador/a tenha antecipado prováveis desenvolvimentos da mesma, incluindo o recurso a determinados procedimentos, não sabe sequer nem pode prever o que realmente irá acontecer nem quais os contornos que a mesma terá - o etnógrafo vai operando por aproximações sucessivas ao objecto de estudo. Significa também que tais dificuldades podem ainda ser extensíveis aos adultos responsáveis pelas crianças, tanto os/as profissionais como os encarregados de educação, uma vez que "nem todas as pessoas conhecem certas partes da pesquisa, nem apreendem com a mesma ou semelhante interpretação tudo o que vai sendo feito" (Burguess, 1997: 50).

13 Talvez essa tenha sido a interpretação que de mim fizeram, pelo menos algumas crianças. Numa ocasião em que a auxiliar de acção educativa repreendeu um pequeno grupo de crianças, dizendo-lhes que não era assim que se falava para a " $D r^{\mathrm{a}}$ Manuela", o Rafael disse-lhe num tom displicente: Dra ? Estagiária, é o que é!" (notas de campo, Maio, 1999)
} 
me saber que apesar de adulta desconhecida eu estava longe de as intimidar porque elas estavam habitudas a lidar e a ser ouvidas por adultos, e que elas, apesar de crianças não só tinham "uma" palavra a dizer como sabiam muito bem como gerir e subverter as situações a seu favor. Ainda que o importante como investigadora tenha sido, naquele momento, ouvir o tão esperado sim, corroborado pelo convite para brincar, sobraram em mim os sentimentos contraditórios e as tensões geradas, e estes têm o valor epistemológico de evidenciar que uma coisa é a teoria e outra é a prática, e que nesta, uma coisa é ainda o que o que se faz e o que se sente, não sendo aí alheia a preponderância que assumem os meus interesses em avançar com a pesquisa face às agruras do trabalho emocional já aqui experimentadas.

Como se tudo isto não bastasse, nesta descrição também está em causa o carácter voluntário inerente à noção de consentimento informado, já que, dadas as circunstâncias institucionais em que se encontram as crianças no JI, elas são, como designa Pugsley (2002: 22), uma "população cativa", estando, portanto, "pragmaticamente [na situação de] participantes cativos". Isto traduz, por parte das crianças, a sua dependência da(s) permissão(ões) adulta(s) e as dificuldades que enfrentam para, naquele momento formal, reflectirem e negociarem deliberada e atempadamente a sua decisão. Não se sabe até que ponto, naquelas circunstâncias, quer a educadora, quer a investigadora conduzem e induzem, ou não, à confirmação da aceitação: sendo crianças há muito familiarizadas com a presença de outros adultos na sua sala ${ }^{14}$, podem, por isso, não ter percebido que podiam recusar as minhas propostas e/ou não estarem à-vontade para recusarem frontalmente e/ou não lhes ter sido dada real oportunidade para tal e/ou de estarem a omiti-lo para agradarem aos adultos. Além destas hipóteses também não será displicente o efeito de conformidade exercido pelo grupo de pares, através do seu coro poderoso, nem as condicionantes temporais que, pela sua

\footnotetext{
14 Este JI costumava receber habitualmente estudantes-estagiários do Curso de Educadores de Infância. Quando iniciei a pesquisa, havia duas alunas naquela condição que iam àquela sala duas vezes por semana durante um período de cerca de 3 meses. Eu ia ao JI nos restantes dias em que elas não iam e ao longo de todo o ano lectivo.
} 
imediatez, redundaram numa aceitação geral, momentânea e circunstanciada. Neste contexto, ficou por esclarecer o valor social daquele "não" singular que se fez ouvir: quereria exprimir uma recusa efectiva? Teria o sentido de me provocar? Ou poderia estar a ser uma forma de desafiar os pares para um não colectivo? Estas e outras ilações não podendo ser sumariamente interpretadas como respostas terminantes, positivas ou negativas, têm o valor epistemológico e ético de mostrar que, perante a elementaridade das informações fornecidas naquele contexto de espaço-tempo e teia de relações, a interpretação do assentimento das crianças é complexa e ambígua, e que a sua confirmação só se poderia esclarecer ao longo do tempo, no decurso da minha relação com elas, através da reflexão crítica das acções e reacções positivas e/ou negativas que manifestassem face às minhas posturas como observadora (cf. Cocks, 2006; Skånfors, 2009).

\subsection{Assentimentos generalizados e cada vez mais sistemáticos, mas diferenciados, parciais e contextualizados}

Na observação participante das interacções das crianças comecei por tomar parte ao lado e com elas nas actividades colectivas que decorreram sob orientação da educadora, passando só depois, quando já estavam dispersas pelas várias actividades livres, individualmente, em pequenos grupos ou em grande grupo, a ocupar um lugar o mais discreto possível, geralmente, numa das mesas do "desenho" ou sentando-me no chão perto da "casinha" ou dos "jogos", para ir registando o que ia observando. Na maioria destas últimas ocasiões as crianças pareceram aceitar que eu as observasse, ignoraram-me, não se coibindo de acesas disputas, conflitos e mesmo confrontos físicos, como se a minha presença lhes fosse indiferente e eu não estivesse sequer ali, ou então, tomaram a iniciativa de me chamar ou vieram até mim para interagirem comigo na sala e no recreio, o que me facilitou entradas reactivas (Corsaro, 1985). Foram situações semelhantes à que descrevo em seguida que me 
permitiram um crescente envolvimento com elas, progredindo da qualidade de observadora à de observadora participante e à de participante observadora:

\begin{abstract}
"[na sala], o Daniel dispõe as cadeiras em duas filas paralelas, trás a tampa de uma panela da "casinha", senta-se numa cadeira da frente, e roda o "volante", emitindo sons de "um motor". - Isto é um autocarro! Eu sou o condutor!anuncia. - Eu também quero ir! - diz o Rafael, sentando-se ao seu lado, e o Francisco, de joelhos, numa cadeira mais atrás, diz: - Eu sou o cão. Eu estou a observá-los sentada a uma mesa, um pouco afastada. O Daniel olha para mim e diz-me: - Não queres vir? De onde estou pergunto-lhe: - Para onde vai esse autocarro?. - Vamos para S. Bernardo! Anda! - responde-me ele. - Ok! - digo eu, levantando-me. Paro em frente ao "autocarro" e faço sinal de paragem. - Entra! diz-me o "condutor". Eu assim faço, sentando-me na cadeira atrás dele. A Joana que tinha estado a observar-nos, põe-se em frente do "autocarro", faz o sinal de paragem e senta-se ao meu lado. "Partimos para S. Bernardo": o Daniel "guia", a Joana olha para mim e ri-se e o Rafael, de vez em quando olha para trás, para mim, e ri-se, até que, passado um bocado, o "condutor" vira-se para trás e diz: Já chegámos! - Muito obrigado! - digo eu, saindo do autocarro. A Joana vem atrás de mim." (notas de campo, 13 de Novembro, 1998)
\end{abstract}

Neste episódio, procuro conciliar os princípios etnometodológicos da indexicalidade e de seguir atrás (tracking) (cf. Coulon, 1987/1995; Waksler, 1991) das crianças, observandoas e escutando-as com atenção para respeitar as suas indicações, e assim me contextualizar o mais possível nas suas brincadeiras, e evitar que, com a minha participação, o curso das suas acções se alterasse. Nesta perspectiva, na experiência da observação participante, a noção de participação remete fundamentalmente para a crescente competência sócio-cultural que o(a) investigador(a) tem de compreender o conteúdo subjectivo das interacções das crianças e de estar simbolicamente implicada nele, de modo a ser capaz de partilhar comummente da significação que dá sentido às acções e actos observados, o que reitera a construção da intersubjectividade como processo intrínseco da etnografia. Assinala-se ainda que, enquanto adulta que aceita brincar com as crianças, ambos permanecemos alvos de observação mútua, ora mais descarada ou mais discreta, como acontece ao longo do jogo, a que acrescem os factores de diversão e reciprocidade que a minha participação lhes parece proporcionar e que, reflexamente, me fazem sentir mais descontraída e confiante. 
A sistematicidade com que a aceitação das crianças à minha presença se foi manifestando alastrou-se igualmente ao recreio. Aqui, salientam-se dois aspectos importantes: a descoberta e acesso pela mão das próprias crianças a um pequeno espaço seu, "escondido" e reservado dos olhares dos restantes adultos da instituição - um tufo de hortênsias 15 -, descobrimento esse que motivou outras reflexões a propósito da privacidade das crianças neste espaço aberto e público:

\begin{abstract}
"Quando cheguei, as crianças brincavam no recreio. Mal passei do portão, o Tiago colocou-me um arco em volta das mãos e disse-me: - Estás presa! Ficas aqui para sempre! Puxando pelo arco leva-me para a "prisão" (o tufo das hortênsias), onde já estavam o Rafael, a Rute, o Daniel e o Lucas. Aí chegados, ele "libertame" as mãos, ordena-me que passe pela estreita abertura que há por entre os ramos das plantas e que me sente no chão. Fiquei um bocado aflita quando vi a estreiteza da passagem que tinha de atravessar, mas depois, com algum cuidado, lá me consegui esgueirar e sentar-me no pequeno espaço livre junto à parede. Ficando à "porta" da "prisão", a tapar a passagem entre as plantas, o Tiago diz às outras crianças que olham para mim um ar espantado: - Ela é a nossa prisioneira!. - És a nossa prisioneira? - pergunta-me o Rafael. Indicando-me o meio da hortênsia, onde já havia uma pequena clareira de tanto uso, a Rute dizme: - És a nossa prisioneira! Então vai prá'li!. - Não posso ficar aqui? - pergunto eu, pois a avaliar pelo meu tamanho seria impossível caber naquele espaço reduzido. Ela olha para mim e diz: - Podes, mas não sais daqui! A brincadeira das crianças prossegue com carregamentos de terra e areia para um carrinho de mão, que peneiram antes de a despejar num monte, e eu ali a observá-las e a tirar notas, e a apanhar "banhos" de poeira, até que o Rafael e o Lucas pegam nos arcos e preparam-se para sair, dizendo o primeiro para o Tiago: - Tu ficas a tomar conta da prisioneira! Quando os outros partiram, ele começou a conversar comigo acerca do local onde morava e do seu avô. (...). Mais tarde, o Lucas e o Rafael, acompanhados do Jorge, com arcos a tiracolo, regressam à "prisão". - O que é que tu estás a fazer, Manela? - pergunta-me o Jorge, admirado. - A Manela está presa. - responde-lhe o Lucas. - Prisioneira, guarda os três arcos! - diz-me o Rafael em voz de comando. E sai da "prisão" com o Jorge. Depois disso, o Lucas e o Tiago, chegam ao pé de mim e dizem: - Vem! Nós tratamos deles! Pegam-me na mão e fugimos da "prisão". Quando passamos junto do Alex que brincava ali perto, ele pergunta-me: - Estás salva?. Respondo-lhe que sim, que o Tiago e o Lucas me libertaram. - Nós protegemos-te! - diz-me o Lucas. E sempre comigo pela mão, levam-me até à caixa de areia. - Tu agora ficas aqui! Nós vamos lá! dizem-me eles, dirigindo-se de seguida para a "prisão". Eu fico à distância a observar o desenrolar do jogo (...)" (notas de campo, 20 de Novembro, 1998)
\end{abstract}

Ir construindo uma perspectiva de "dentro" das culturas infantis é uma tarefa difícil: a presença do adulto-investigadora nos mundos das crianças pode até ser desejada e aceite por

\footnotetext{
15 Tratava-se de um canto, num declive ao fundo do jardim, onde havia um grande tufo de hortênsias, tão cerrado que quem passava pelo caminho junto dele não via as crianças que brincam dentro e atrás dele, no espaço livre entre ele e uma parede. Durante o recreio os adultos da instituição costumavam permanecer na parte mais alta do recreio, entre a caixa de areia, e o edifício do JI, o que colocava este local fora do seu ângulo de visão e audição.
} 
algumas delas, mas constitui um desafio permanente a vários níveis. Pela primeira vez, fui confrontada com as diferenças óbvias de tamanho físico e com os constrangimentos daí decorrentes em termos de agilidade e maleabilidade, por exemplo, que me obrigaram a ter de negociá-lo com a Rute para poder ali permanecer. É esta presença desusada de uma adulta num espaço que até então permanecera um reduto secreto das crianças que parece estar na origem da sua surpresa; surpresa essa reiteradamente esclarecida pelo Tiago que me atribuiu um papel muito específico no jogo, como "prisioneira". Nesta qualidade, não me sendo exigido nada mais do que ficar sob jurisdição das crianças, "presa", procurei que a minha participação observante fosse coerente com o papel de "prisioneira", visando assim atenuar o mais possível as diferenças de poder que como adulta representava, mas, todavia, sem abdicar completamente de prosseguir, como adulta-investigadora, a recolha de informações. A tentativa de compatibilizar ao máximo os interesses em jogo, os inerentes à construção da relação social de investigação com as crianças e os inerentes à realização da minha pesquisa, naquela oportunidade que inesperadamente se tinha aberto, representa um esforço não isento de experiências pessoais menos agradáveis e, a partir de um dado momento, geradoras de alguma tensão, como foi a situação do "banho" de pó sem queixumes, mas que a prolongar-se por muito mais tempo eu antevia como insustentável para mim. A carga emocional que a observação participante agudiza não reside apenas nessa "espécie de duplicidade" que atinge a pessoa da investigadora na "prática dessa décalage" (Cabral, 1983: 333), mas abarca também a esfera dos seus sentimentos pessoais, neste caso, de aversão à poeirada que se me entranhava pelo corpo. As tensões entre o manter a face, lidando interiormente com os meus dilemas e com a ambiguidade das minhas identidades, erguem-se quando o intervalo de tolerância dos meus interesses como investigadora com crianças se confronta com os meus limites pessoais na pesquisa: no primeiro caso, se o mais importante era poder ficar e acompanhar o que se passava dentro do espaço privado que as crianças criaram no espaço 
público do recreio e, como participante no jogo, entendia que peneirar a terra fazia sentido naquele contexto de jogo lúdico, no segundo caso, as consequências que essa posição de sujeição acarretava ameaçavam entrar em choque e deitar por terra o esforço de racionalização dos sentimentos que tal me começava a exigir. Nesta situação fica patente que além do corpo há outras diferenças sócio-culturais e afectivas mais subtis que entram em jogo na relação de investigação entre adultos e crianças e que, tão importante como a aceitação do adulto pelas crianças é também a aceitação e as concessões que a própria pessoa do adulto está disposta a fazer no decurso da observação participante, sendo que nenhuma delas tem seguro de garantia ilimitado.

Decorre daqui uma outra ilação importante: a de que os processos de aceitação do adulto pelas crianças são diferenciados e têm sentidos diferentes, expressando modos de aceitação activa, como é o caso do convite endereçado pelo Tiago; de aceitação activa previamente contextualizada, como acontece com a pronta confirmação da Rute face à minha presença naquele espaço e jogo, e com a "libertação" que o Tiago e o Lucas se dispõem a fazer da minha pessoa e personagem, mas, igualmente, modos de aceitação tácita por influência interpares, como ocorre nas surpresas e interrogações iniciais das restantes crianças e sua aceitação pontual depois de esclarecidas pelos seus parceiros de jogo.

Ao lidar com todas estas diferenças, deparo-me ainda, nesta participação observante como "prisioneira", com a necessidade de reconceptualizar e recontextualizar o argumento ético da privacidade das crianças, frequentemente reduzido pelos adultos ao âmbito da salvaguarda dos direitos de anonimato e confidencialidade de informações de carácter individual. Num espaço e situação públicos como é o recreio e nas acções sociais que ali têm lugar, naquilo que aos olhos dos adultos do JI não passava de um ornamento paisagístico do recreio - as hortências -, as crianças tinham-no ressignificado, criando um outro espaço cuja reserva e, até então, inacessibilidade visual e física a "estranhos", o manteve dissimulado, 
mas à vista de toda a gente. Os encontros sociais que ali ocorreram e que tive oportunidade de observar, não contendo "ingredientes especiais" ou muito diferentes dos que aconteciam na sala do JI, colocaram-me todavia perante a necessidade de alargar a definição adulta do que contava como espaço de privacidade para o(s) grupo(s) de crianças, e de entrar em linha de conta com a expressão de concepções infantis, na sua especificidade e como dependentes do nível e dos sentidos de privacidade por elas atribuídos (cf. Robson \& Robson, 2002: 102). A descoberta destes outros espaços e relações de privacidade das crianças podem originar dilemas éticos acerca dos poderes e responsabilidade que, no limite, a posse daqueles conhecimentos pelos(as) investigadores(as), e a sua divulgação ou não, lhes confere perante as crianças e a educadora. Em ambos os casos, pode correr-se o risco das relações de confiança, consideração e respeito entretanto estabelecidas poderem ser perturbadas e comprometer a pesquisa. Porém, a confidencialidade absoluta também tem os seus problemas e estes podem ser graves quando surgem questões em torno da protecção das crianças (cf. France, Bendelow \& Williams, 2000: 160).

\subsection{Recusas e resistência sob a forma de provocações}

No decurso da observação participante aconteceu, por vezes, que as mesmas crianças que habitualmente tomavam a iniciativa de se aproximarem e de me convidarem a participar nas suas interacções, ou que nelas me aceitaram, mudavam de ideias. A fluidez das perspectivas das crianças no que respeita à decisão da aceitação ou recusa da presença da adulta-investigadora parece jogar-se tacitamente na interdependência entre a existência de interpretações diferenciadas no(s) grupo(s); de posições divergentes face à sua presença e de circunstâncias específicas que num determinado momento, lugar, objectos, participantes ou acção se conjugam.

Contrastando vivamente com o não singular, mas audível, que se fez ouvir no meu primeiro dia, e também com a minha experiência noutro JI em que detectei expressões de 
recusas veladas à minha observação por parte de crianças - virarem-se de costas e falarem entre-dentes ou baixarem o tom de voz, e/ou mudarem de assunto ou de lugar, e/ou colocarem-se em círculo fechado, por exemplo (cf. Ferreira, 2004) -, aqui fui sobretudo confrontada com recusas directas ou em que a resistência à observação se socorreu da estratégia de provocação, mostrando, à semelhança do episódio que se segue, que as crianças pequenas são capazes de se expressar, de muitas maneiras, quando não querem tomar parte na pesquisa:

\begin{abstract}
"O Pedro trouxe um comboio a pilhas para a sala (...). [mais tarde], ele, o Tiago e o Francisco vão para "os jogos" e movem o comboio fazendo com que choque contra umas peças de Lego, que estão espalhadas no chão. - Foguetões! Foguetões de S. Majestade! - diz o Tiago, enquanto atira peças ao ar. O Rafael, que está ao lado, vê-me a observá-los e atira-me uma peça enquanto olha para mim, mas eu limito-me a manter o olhar. Nessa altura, o Tiago pergunta-me: - O que é que estás a escrever?. - $O$ vosso jogo! - digo-lhe eu e leio-lhe o que ele tinha dito. Ele parece surpreso e grita aos outros rapazes: - A Manela está a escrever! A Manela está a escrever! Pára esse jogo! Vamos à Manela!. Nisto, chega a Kim, que lhes mostra um telemóvel que tinha trazido de casa. Os rapazes precipitam-se para ela, mas eu mudo de lugar." (notas de campo, 26 de Fevereiro, 1999)
\end{abstract}

Nesta situação a recusa das crianças em serem observadas é-me comunicada de vários modos. No caso do Rafael, tratou-se de uma recusa não verbal directa, expressando uma agressão, quando, ao dar-se conta que observo os seus amigos num uso dos objectos que era "proibido" na sala do JI, adopta uma atitude de cumplicidade e protecção para com eles. Falando mais alto que as palavras, o gesto que me dirigiu foi por mim entendido como sendo um claro sinal dissuasor para prosseguir a observação; sinal esse eivado de um sentido de provocação 16 , como que para "avaliar" qual seria a minha reacção face à eminência de ser atingida pela peça de Lego. Ora, o mesmo gesto agiu como uma espécie de alerta para os outros rapazes, avisando-os da minha presença. Em consequência, o Tiago começa por

\footnotetext{
16 Pontualmente aconteceu também que, algumas meninas mais velhas, criaram situações provocatórias a propósito da minha pessoa, como que a testarem-me para ver qual seria a minha reacção. Esse era sobretudo o caso do duo Bruna e Mafalda. Por exemplo, "quando estou sentada na mesa dos "desenhos" a observar o que se passa na "casa" a Bruna que faz um desenho comenta-o para a Mafalda, dizendo: "Esta é a Manela a fazer xi-xi e agora vou fazer a Manela com as mamocas ao léu". Elas olham para mim e desatam a rir-se às gargalhadas. Eu finjo que não as ouvi.” (notas de campo, 6 de Março, 1999)
} 
confirmar comigo a minha acção e só após a minha resposta expressa a sua recusa. Formulando uma pergunta que era recorrente as crianças fazerem-me, e à qual eu sempre respondia aproveitando para esclarecer o meu papel como investigadora e para validar as minhas interpretações, parece ser o seu confronto com a devolução que lhe faço da sua voz que gera a sua tomada de consciência de que estava a ser alvo de observação e a decisão de recusa que se seguiu. Esta recusa, ao contrário do Rafael, é(-me) duplamente comunicada: primeiramente, de um modo verbal mas indirecto já que se dirige ao grupo de rapazes, dandolhes indicações para pararem o jogo porque eu estava a reportá-lo, sucedendo-se depois um outro tipo de recusa verbal, directa a mim, em que o discurso da ameaça/provocação parece ser mobilizado, subentendendo o acompanhamento de uma acção visando a minha pessoa: Vamos à Manela!. Não obstante a chegada da Kim tenha atraído as atenções dos rapazes, desviando-as de mim e reduzindo a minha presença a uma inusitada insignificância, passando subitamente para secundaríssimo plano, retirei-me.

A rapidez com que se inverteu completamente a extrema visibilidade e importância que a minha presença tinha adquirido é reveladora da fluidez que caracteriza o fluxo das acções sociais das crianças pequenas e da centralidade que nelas assumem as conjunturas relacionais. Para todos os efeitos, considerei que nesta situação, a tomada de consciência da minha presença fora interpretada como uma invasão do seu espaço social e uma intromissão num assunto de crianças e a elas reservado: observar uma transgressão das regras institucionais, tornava-me aos seus olhos uma representante do poder e autoridade atribuídos socialmente aos adultos. Ora, a acção observada desenrolou-se numa área da sala sem quaisquer barreiras físicas que a ocultassem, co-existindo aliás, a par com todas as outras que ali decorriam. Este aparente paradoxo reenvia novamente ao entendimento da noção de privacidade como sendo gerada nos modos como ela é percebida, experimentada e conotada pelas próprias crianças que nela estão envolvidas e participam, ou seja, brincar a atirar peças 
de Lego ao ar estaria a ser percebido por aquelas crianças como uma brincadeira sua, privada, independentemente de ocorrer num espaço aberto, colectivo e com livre circulação. O que constitui ou não um encontro ou um domínio de privacidade das/pelas crianças não pode ser então completa e exclusivamente definido à priori nos termos adultos, nem de modo estanque e exterior ao contexto simbólico das acções infantis. Tal como em relação à obtenção do assentimento das crianças, também a salvaguarda da sua privacidade requer que se busque o entendimento delas a todo o momento e sempre no respeito pelos enquadramentos conceptuais que vão dando sentido ao fluxo das interacções entre pares nas suas várias circunstâncias.

\section{Considerações finais}

Entendendo a etnografia como "uma descrição informada de pessoas e do seu modo de viver no mundo" (Jenks, 2000: 68) que não se resume a um conjunto de vozes concertadas e, muito menos, no caso das crianças pequenas, a uma recolha de expressões hilariantes para gáudio dos adultos, procurou-se neste texto recontextualizar e repensar os princípios do consentimento informado voluntário e da privacidade na perspectiva das crianças. Neste sentido, e face aos limites que a sua realização e/ou percepção coloca no decurso da observação participante apontaram-se as vantagens ético-metodológicas em assumir a noção de assentimento, entendida como processos em curso para obter a permissão das crianças a fim da sua observabilidade ser por elas aceite.

Permanecendo em debate a questão das competências das crianças para darem o seu acordo na pesquisa, sobretudo quando são crianças pequenas, procurou-se aqui situar aquele conceito para além dos limites e diferenças que pudessem apresentar, reconhecendo as dependências, incompetências e incompletudes como constituintes da (sua) acção social (cf. Cocks, 2006). Situar as competências das crianças é entendê-las como actores sociais, posicionando as suas acções - fazer e dizer as coisas, os saberes que evidenciam e os sentimentos expressos, as interpretações e avaliações dos outros e a defesa das suas acções e 
dos seus pontos de vista - nessa indissociabilidade de uso que elas fazem da sua experiência acumulada e das suas competências comunicativas actuais, em função e em relação aos contextos em que se dão os seus encontros (cf. Ferreira, 2004). Reafirma-se assim a importância dos(as) adultos-investigadores(as) escutarem "as vozes" das crianças "para ser[em] capaz[es] de interpretar, traduzir, mediar os sentidos intersubjectivos possíveis nos processos comunicativos (...) trata-se de prestar sentido e não de o impor, numa postura de cuidado, abertura ao outro e deslocação da atenção para a pessoa, na qualidade de pessoa complexa, e não para as categorias sociais que pesam sobre ela" (Ferreira \& Rocha, 2010: 15), para assim respeitarem a sua integridade ao longo da pesquisa. Ora, isso implica assumir que a negociação da sua presença não se circunscreve nem limita apenas a um único momento - habitualmente a negociação inicial que formaliza a entrada do(a) investigador(a) no terreno. A obtenção do assentimento por parte das crianças, malgrado todas as faltas e falhas de informação que possam existir, depende grandemente da relação de confiança estabelecida com o(a) investigador(a), pelo que a aceitação da sua presença, além de ter de ser permanentemente activada e renegociada ao longo da pesquisa terá de ser reflectida criticamente em função da receptividade e reciprocidade e/ou rejeições que desencadeie. Ao mesmo tempo, importa desenvolver e accionar uma sensibilidade ética capaz de interpretar as decisões das crianças de modo diferenciado e socialmente contextualizado, na medida em que os(as) vários(as) actores, com diferentes níveis de competência e conhecimento, de interesses, papéis e poderes e de capacidades de acção, experimentam realidades sociais de algum modo distintas, mesmo quando participam juntos na mesma interacção.

Condição ética inerente à realização da pesquisa, os processos de obtenção da permissão o mais informadamente possível por parte dos adultos e das crianças tornam então a sua reflexão indispensável por várias ordens de razões: para se perceber os efeitos da estrutura geracional na pesquisa e os limites que se colocam à noção de consentimento 
informado com crianças pequenas; para se perceber "os efeitos disruptivos que a pesquisa causa no decurso normal das rotinas e práticas culturais (...); [e que] a entrada, a aceitação e a participação são processos com histórias em desenvolvimento" (Corsaro \& Molinari, 1999: 523), deles dependendo os modos como as pessoas investigadas percebem e definem a pesquisa e a pessoa e actividades do(a) investigador(a) (cf. Burguess, 1997: 48), e para perceber que a obtenção da permissão das crianças, não se cingindo à sua mera formalização num momento inicial da pesquisa, requer que o(a) investigador(a) aprenda a conhecer as suas decisões tácitas a esse respeito e ao longo da sua permanência no terreno, escutando as suas vozes e mobilizando aquilo que Skånfors (2009: 15) designa por "radar ético”, uma espécie de alerta sensível aos vários modos pelos quais as crianças podem expressar a sua resistência e recusas em serem observadas.

Na compreensão dos processos de obtenção do assentimento das crianças pequenas como sendo contextualizados mas fluidos e diferenciados por/entre crianças ou grupos de crianças sobrevêm as relações de interdependência tecidas na pesquisa etnográfica entre a adulta-investigadora e as crianças-investigadas, e com elas a consciência de que a intersubjectividade construída é sempre relativa, aproximada e imprecisa. Assim sendo, a construção social da realidade é sempre um processo aberto e vulnerável à ambiguidade, à incompreensão, ao conflito, à incerteza, e "se essa incerteza pode ser assustadora para alguns, ela fornece ao investigado uma lente clara para explorar o mundo social. Ela facilita o pensamento lateral e uma abertura para novos modos de pensar acerca da adultez e da infância” (Cocks, 2006: 255).

- SHE'S OUR PRISONER! - THEORICAL, EPISTEMOLOGICAL, ETHIVAL AND METHODOLOGICAL ISSUES ABOUT YOUNG CHILDREN'S ASSENT TO ETHNOGRAPIC RESEARCH

\author{
Abstract \\ Revista Reflexão e Ação, Santa Cruz do Sul, v.18, n2, p.151-182, jul./dez. 2010
}


Subscribing the Sociology of Childhood approach that considers children as social actors and advocates ethnography as an useful methodology to let children's voices to be heard in sociological data production (James \& Prout 1990), this text reflects about some epistemological, theoretical, methodological and ethical issues inherent to field work with children aged from 3-6, taken during a school year in a kindergarten located in urban area. Focusing on the theoretical and ethical principle of informed consent and its practice with young children, the text discusses tensions and boundaries between this principle and the one of assent in the course of participant observation. The analysis of children's assents and refusals and the configurations that may take over the research, seeks to show the assent processes as contingent, heterogeneous and dependent on the social relations built on research context as well as interpretations that children weave about the person of the researcher.

Keywords: Childhood; research methodology; ethnography.

\section{Referências}

ALDERSON, Priscilla; MORROW, Virginia. Ethics, social research and consulting with children and young people. Tanners Lane, Barnardo's, 2004.

BRACK-LAMY, Maria G. Da magia da noite à magia/desencanto da cama. Oeiras, Celta Editora, 2009.

BURGUESS, Robert. A pesquisa no terreno. Oeiras, Celta Editora, 1997.

CABRAL, João P. Notas críticas sobre a observação participante no contexto da etnografia portuguesa. Análise social, vol XIX (76), p. 327-339, 1983.

CHRISTENSEN, Pia. Children's participation in ethnographic research: issues of power and representation. Children and Society, vol. 18, p. 165-76, 2004. 
CHRISTENSEN, Pia; PROUT, Alan. Anthropological and Sociological perspectives on the study of children, in Greene, S. \& Hogan, D. (ed.). Researching children's experiences, approaches and methods. London, Sage, p. 42-60, 2005.

COCKS, Alison. The ethical maze: finding an inclusive path towards gaining children's agreement to research participation, Childhood, vol. 13 (2): 247-266, 2006.

CORSARO, William. Friendship and peer culture in the early years. Norwood: Ablex Publishing Corporation, 1995.

CORSARO, William. Sociology of Childhood. London: Pine Forge, 1997.

CORSARO, William; MOLINARI, Lisa. Entering and observing in children's worlds: a reflection on a longitudinal ethnography of early education in Italy, in Christensen, Pia \& James, Allison (eds). Research with children, perspectives and practices. London: Falmer Press, 179-200, 1999.

COULON, Alain. Etnometodologia, Petrópolis: Vozes (1995).

FERREIRA, Manuela. Os estranhos 'sabores' da perplexidade numa etnografia com crianças, in Caria, T. Metodologias etnográficas em Ciências Sociais. Porto, Edições Afrontamento, p. 149-166, 2003.

FERREIRA, Manuela.“A gente gosta é de brincar com os outros meninos!”- relações sociais entre crianças no Jardim de Infância. Porto, Edições Afrontamento, 2004.

FERREIRA, Manuela. "Branco demasiado" ou... reflexões epistemológicas, metodológicas e éticas acerca da pesquisa com crianças, in Sarmento, M. J. \& Gouvea, M. C. S. "Estudos da Infância, educação e práticas sociais”. Petrópolis, Vozes, p. 143-162, 2004.

FERREIRA, Manuela; ROCHA, Cristina (2010). As crianças e a infância na Sociologia da Infância em Portugal - contributo para uma análise da produção científica (1995-2005), (no prelo).

FINE, Gary; SANDSTROM, Kent L. Knowing children, participant observation with minors. London. Sage, 1988.

FRANCE, Alan; BENDELOW, Gill; WILLIAMS, Simon. A 'risky' business: researching the health beliefs of children and young people, in Lewis, Ann and Lindsay, Geoff (Eds.) Researching Children's Perspectives. Buckingham: Open University Press, p. 150-162, 2000.

GALLAGHER, Michael. Ethics, in Tisdall, E.K. M., Davies, J. \& Gallagher, M., Researching with children \& young people, research, design, methods and analysis. London, Sage, p.11-66, 2006.

GEERTZ, Clifford (1973).Interpretación de las culturas. Barcelona: Gedisa Editorial, 1941. (1999). 
GOFFMAN, Erwing (1961). Manicómios, prisões e conventos. São Paulo: Ed. Perspectiva (1974).

GOFFMAN, Erwing. A Apresentação do eu na vida de todos os dias. Lisboa: Relógio d'Água, 1993.

JAMES, Allison; PROUT, Alan. Constructing and Reconstructing Childhood, Contemporary Issues in the Study of Childhood. London, The Falmer Press, 1990.

JAMES, Allison, JENKS, Chris; PROUT, Alan. Theorising childhood. London: Polity Press, 1998.

JAMES, Allison; CHRISTENSEN, Pia. (eds.). Research with children - perspectives and practices. London, Falmer Press, 2000.

JAMES, Allison. Give a voice to children's voice: practices and problems, pitfalls and potentials. American Anthropology, vol. 109, Issue 2, p. 261-272, 2007.

JENKS, Chris. Zeitgeist research on childhood, in James, Allison \& Christensen, Pia (2000) (eds.). Research with children - perspectives and practices. London, Falmer Press, p. 62-76.

JONES, O. Before the dark of reason: some ethical and epistemological considerations on the otherness of children. Ethics, Place \& Environment. 4: 2, p. 173-178, 2001.

LINDSAY, GeofF. Researching children's perspectives: ethical issues, in Lewis. Ann and Lindsay. Geoff (Eds.) Researching Children's Perspectives. Buckingham: Open University Press, p. 1-20, 2000.

MACHADO, José Pedro. Dicionário Etimológico da Língua Portuguesa com a mais antiga documentação escrita e conhecida de muitos dos vocábulos estudados. $7^{a}$ edição 1995, Lisboa, Livros Horizonte, vol I e vol II, p. 334 e 213, 1952.

LLOYD-SMITH, M.; TARR, J. Researching children's perspectives: a sociological dimension, in Lewis. Ann and Lindsay, Geoff (Eds.). Researching Children's Perspectives. Buckingham: Open University Press, P. 59-70, 2000.

MANDELL, Nancy. 'The least-adult role in studying children', in WAKSLER, F. C. (ed.), Studying the Social Worlds of Children - sociological readings, London: The Falmer Press, p. 38-59, 1991.

MASSON, Judith. Researching children's perspectives: legal issues, in Lewis, Ann and Lindsay, Geoff (ed.), Researching children's perspectives. Buckingham, Open University Press, p. 34-45, 2000.

MAYALL, Berry. Conversations with children: working with gerational, in James, Allison \& Christensen, Pia (2000) (eds.). Research with children - perspectives and practices. London, Falmer Press, p. 120-135, 2000.

PROUT, Alan. Forword, in in James, Allison \& Christensen, Pia (2000) (eds.). Research with children - perspectives and practices. London, Falmer Press, p. XI-XXI, 2002. 
PUGLEY, Lesley. Putting your oar in: moulding, muddling or meddling?, in Welland, Trevor \& Lesley, Pugsley (edts.), Ethical dilemas in Qualitative Research. Cardiff papers in qualitative research. Aldershot, Ashgate Publishing Company, p. 19-31, 2002.

QVORTRUP, Jens. Macroanalysis of childhood, in James, Allison \& Christensen, Pia (2000) (eds.). Research with children - perspectives and practices. London, Falmer Press, p. 77-97, 2000 .

RENOLD, Emma. Privacies and private: making ethical dilemmas public when researching sexuality in the primary school, in Welland, Trevor \& Lesley, Pugsley (edts.). Ethical dilemas in Qualitative Research, Cardiff papers in qualitative research. Aldershot, Ashgate Publishing Company, p. 121-134, 2002.

ROBSON, K.; ROBSON, M. Your place or mine? Ethics, the researcher and the internet, in Welland, Trevor \& Lesley, Pugsley (edts.). Ethical dilemas in Qualitative Research, Cardiff papers in qualitative research. Aldershot, Ashgate Publishing Company, pp: 94107, 2002.

SILVA, Pedro. Etnografia e educação, reflexões a propósito de uma pesquisa sociológica. Porto. Profedições, 2003.

SKANFORS, Lovisa. Ethics in child research: children's agency and researchers' 'ethical radar'. Childhoods Today. Vol. 3 (1), p. 1-22, 2009.

WAKSLER, Francis. C. (1991) (ed.), Studying the Social Worlds of Children - sociological readings. London: The Falmer Press, 1994.

WELLAND, Trevor; LESLEY, Pugsley. (edts.). Ethical dilemas in Qualitative Research, Cardiff papers in qualitative research. Aldershot, Ashgate Publishing Company, 2002.

Data de recebimento: $23 / 07 / 2010$

Data de aceite: 21/09/2010 